\title{
ASSISTENCIA DE ENFERMAGEM A CRIANÇAS HOSPITALIZADAS QUANDO ENFRENTAM SITUAÇÕES DESAGRADÁVEIS (PARTE I)
}

\author{
Dyrce Maria Rocha Martins* \\ Alice Eico Ohki** \\ Vanda Elisa Andres Felli**
}

MARTINS, D. M. R.; OHKI, A. E.; FELLI, V. E. A. Assistência de enfermagem a crianças hospitalizadas quando enfrentam situações desagradáveis (parte 1). Rev. Esc. Enf., USP, São Paulo, 13(2): 157-169, 1979.

São apresentados relatos de experiências de alunos cursando Enfermagem Pediátrica, nas quais é dado apoio a crianças hospitalizadas que enfrentam situações desagradáveis $e$ dificeis. Neste artigo - primeiro de uma série - são relatadas duas experiências em que as crianças são submetidas à passagem de sonda naso-gástrica.

\section{INTRODUÇÃO}

A criança doente e hospitalizada geralmente está sujeita a uma série de experiências desagradáveis, quer de exames para diagnóstico, quer de tratamento. A própria doença e a hospitalização sāo ocorrências, em sua vida, muito difíceis de serem vividas. Nestas situações, a criança necessita de apoio emocional especial; caso contrário a sua saúde mental pode ser afetada.

Segundo BELLACK ${ }^{2}$, criança tem recursos limitados para enfrentar sozinha situações estressantes, devido ao seu desenvolvimento imaturo. "Para superar o medo e o sofrimento, geralmente recorre à fantasia, uma vez que sua capacidade de raciocinar logicamente e considerar os fatores pertinentes à situação é limitada". Afirma, ainda, que a maneira como cada criança enfrenta a dor e a ansiedade depende não só de seu desenvolvimento mas também das experiências anteriores relacionadas a doença, traumas, hospitalizações e conceitos que tem a respeito do pessoal de saúde.

SMITH ${ }^{7}$, baseada em conceitos do desenvolvimento da personalidade, faz sugestóes práticas sobre o modo de dar apoio e afirma que "a quantidade e a espécie de apoio emocional que cada criança necessita depende da resistência de seu ego, pois a maneira como cada criança responde é determinada por forças internas e externas"; sugere a utilização do brinquedo como instrumento extraordinário para assistir à criança em situações estressantes. Para fundamentar essa sua afirmação, apresenta a opinião de três autores, a seguir referidas. Segundo ERIKSON 4, "brincar é o meio mais natural e auto-cicatrizante na infância"; para PIAGET 6 , a repetição no brinquedo da situação dolorosa tem a finalidade de tornar a dor suportável para a criança, através da assimilação do seu ego; e BARTON ${ }^{1}$ firma que a situação de brincar de boneca pode reduzir os efeitos produzidos pelas experiências do hospital na criança".

* Professor Assistente da disciplina Enfermagem Pediátrica da EEUSP. Mestre em Enfermagem.

Aluna do Curso de Graduação da Escola de Enfermagem da USP, cursando a disciplina Enfermagem Pediátrica em 1977. 
BELLACK ${ }^{2}$ menciona outros meios que devem ser utilizados para auxiliar a criança a enfrentar uma situação traumática ou dolorosa. Suas sugestões são:

- informar a criança sobre o que ela deve esperar e como deve participar;

— envolver a criança na situação, em vez de tratá-la como objeto passivo;

— permitir à criança expressar seus sentimentos, evitando, porém, contribuir para suas fantasias;

- permitir à criança manipular o material da experiência previamente e/ou posteriormente;

- dar a criança alternativas de evasão para sua dor durante a experiência dolorosa, como por exemplo: "você pode chorar quando sentir dor ou apertar fortemente minha mão";

- reforçar as tentativas de cooperação da criança e jamais puníla ou repreendê-la nos casos de incapacidade de cooperar ou nos casos de insucessos;

- manter fisionomia tranqüila diante da criança; e

- envolver os pais nos cuidados da criança, desde que sejam capazes de controlar sua ansiedade diante do filho ao viver a situação dolorosa ou desagradável, pois os pais conhecem os filhos melhor que a enfermeira e podem ter maior sucesso para interpretar o que está acontecendo com a criança.

Para WU ${ }^{8}$, a preparação mental do paciente inclui 4 categorias de informações, a saber:

— informação do fato que está para acontecer;

- predição do que o paciente provavelmente vai experimentar;

- transmissão de confiança na forma de afirmações otimistas; e

- recomendação que proporcione possibilidade de controle da experiência, e, desse modo, reduza os sentimentos de abandono.

A referida autora indica como estas categorias de informação podem ser aplicadas na assistência de pacientes de 2 a 8 anos, levado em consideração o desenvolvimento do pensamento deles.

Durante as experiências de campo de Enfermagem Pediátrica, os estudantes do curso de graduação têm oportunidade de auxiliar crianças hospitalizadas que enfrentam situações desagradáveis, dolorosas ou difíceis, principalmente, em unidades de cirurgia.

Em sala de aula, são dadas aos estudantes informações básicas sobre: princípios científicos que devem ser levados em consideração, material e métodos que podem ser utilizados para assistir crianças nas situações desagradáveis mais freqüentes no hospital e como utilizar o guia de estudo, MORAES 5 , para a elaboração do trabalho teórico-prático. No campo de prática a docente auxilia os estudantes a planejar e prestar assistência a crianças, antes, durante e após experiências desagradáveis a serem vividas por elas.

A tarefa a ser desenvolvida pelos alunos tem como objetivo levá-los a se comunicarem efetivamente com a criança nessa situação. 
Percebe-se, muitas vezes, que o aluno, diante das manifestações das crianças, ou da situação propriamente dita, ou devido a sua inexpriência de lidar com criança, põe em dúvida se a assistência propositada nestas circunstâncias pode realmente auxiliar a criança até o ponto de conseguir sua participação ativa na experiência. Entretanto, parece ser uma das atividades mais gratificantes e significativas para os estudantes, uma vez que os resultados por vezes são surpreendentes.

Para demonstrar o quanto é importante a assistência de enfermagem à criança que enfrenta experiências desagradáveis, decidimos apresentar uma série de relatos de experiências dos alunos durante a prática de campo em Enfermagem $\mathrm{Pe}$ diátrica, em diferentes épocas.

Nesta primeira oportunidade apresentaremos duas experiências na assistência de crianças doentes hospitalizadas submetidas à passagem de sonda naso-gástrica.

\section{RELATOS DE EXPERIENCIAS DOS ALUNOS}

\section{Experiência n. ${ }^{\circ} 1$}

Nome: W.C.S. Idade: 6 anos. Sexo: masculino. Procedência: Santo André, SP

W. é uma criança sociável, brinca com todas as crianças da clínica, é carinhosa, não é egoísta. Adapta-se bem ao meio ambiente e é espontânea no seu relacionamento com o pessoal da clínica. Sua linguagem é adequada à sua idade, fala pouco.

Tem capacidade para compreender as explicações que lhe são dadas a respeito de sua hospitalização.

Esta é a 6. ${ }^{a}$ internação de W. Em seu comportamento nada há que demonstre dificuldade de adaptação ao meio ambiente: coopera com a equipe de saúde, aceitando as medicações e enfrentando bem as situações de provas e exames. Ao ser indagado sobre o que pensa do hospital, disse que gosta mais deste do que do outro, que não permitia a visita dos pais dentro da enfermaria, mas somente, através do vidro; informa gostar da alimentação do hospital porque é semelhante à de sua casa, só que a comida que a sua mãe faz é mais gostosa; e refere sentir saudade dos irmãos (7) e dos sobrinhos (3).

Na sua história clínica $W$.tem, como diagnóstico inicial, úlcera péptica com estenose de duodeno. Devido a este diagnóstico, W. já foi hospitalizado seis vezes e operado duas vezes: gastrectomia a Billroth II e vagotomia troncular. Atualmente ainda apresenta úlceras pépticas jejunais. Como principal manifestação tem dor localizada no flanco esquerdo, o que o leva a ser medicado freqüentemente com analgésico e a passar por vários exames radiológicos e de laboratório.

Considerações sobre a experiência desagradável a ser vivida pela criança.

A experiência a ser vivida por $W$. é uma prova de colheita de suco gástrico. criança:

Nesta situação são identificadas as seguintes fontes de desconforto para a 
- passagem da sonda naso-gástrica;

- náuseas e vômitos, intercorrências que podem suceder durante a introdução e permanência da sonda;

- a duração da prova: 1 hora e 45 minutos;

- a posição em decúbito lateral, em que $W$. deve permanecer durante toda a prova;

- o local onde é realizada a prova: sala pequena, pouco ventilada, e o grande número de pessoas que circulam pelo recinto;

- o jejum durante várias horas, após dois dias de dieta liquida.

Apesar de W. já ter passado pela experiência anteriormente, esta não deixa de ser desagradável e difícil para ele. Diante das muitas fontes de desconforto identificadas para esta situação, considerei importantes o preparo psicológico e o apoio emocional a serem dados a esta criança. Os objetivos da assistência de enfermagem para W. nesta situação foram:

- prepará-lo psicologicamente para a experiência;

- oferecer-lhe apoio durante o exame;

- proporcionar-lhe oportunidade de manifestar seus sentimentos a respeito da situação.

Planejamento da conduta de enfermagem antes, durante e após a experiência.

O preparo psicológico da criança constaria de: explicar-lhe, com palavras simples, como seria realizado o exame e a que se destinaria, visando evitar sua tensão emocional; fazer dramatização de introdução de sonda gástrica num boneco; darlhe oportunidade de manipular o material; informá-la da necessidade do exame; e orientá-la quanto aos procedimentos para que ela pudesse atuar, juntamente com o médico, como por exemplo, na introdução e retirada da sonda, levando-a a perceber a sua capacidade de ação e a despertar nela a auto-confiança.

Durante a prova, oferecer apoio à criança, permanecendo ao seu lado, demonstrando confiar nela, compreedendo seus comportamentos; atendendo às suas solicitações e respondendo às suas perguntas. Cooperar com o médico responsável pelo exame, informando-o das solicitaçóes da criança e facilitando o andamento do mesmo.

Após o exame, criar oportunidade para fazer comentários a respeito do que ocorreu durante o mesmo, por exemplo, comentar sua atitude de cooperação; permitir-lhe manifestar seus sentimentos a respeito da situação vivida; dar-lhe oportunidade de descarregar sua tensão emocional através da dramatização no boneco; perguntar-lhe se houve alguma coisa diferente das informçaões que havia recebido.

Descrição do comportamento da aluna e da criança frente à experiência.

Antes de chegar ao local do exame W. mostrava-se calmo, sem comportamento que demonstrasse tensão emocional, medo ou insegurança. 
Na sala de exame mostrou-se um pouco inseguro, procurou apoio, segurando a minha mão, encostando-se em mim e, às vezes, procurando também a mão do médico. (Estes gestos parecem demonstrar que ele confiava em nós.)

$\mathrm{O}$ diálogo que segue mostra o tipo de interação que houve entre o médio (D), a aluna (A) e a criança $(\mathrm{C})$.

D - Você já sabe como vai ser o exame?

C - Já.

A - Eu expliquei ao W. como vai ser o exame. Você está com medo W.?

C - Não!

O médico observou o boneco e a sonda que estavam juntos ao nosso material de estudo e comentou:

D - Você já passou a sonda no boneco?

C - A tia trouxe o boneco. (Olhou em minha direção.) Eu só comecei a passar a sondinha.

De fato W. apenas começara a passar a sonda no boneco, pois o interno avisara, naquele momento, que estava na hora de W. descer para o exame.

A - Você quer passar a sonda no boneco, enquanto nós esperamos para começar o exame?

C - Agora não, tia, lá em cima eu passo a sonda.

D - Você gosta de jogar bola?

C - Eu gosto! Quando eu estou em casa jogo com meus irmãos.

D - Você tem muitos irmãos?

C - Tenho 7 irmãos.

D - Tudo isso? Bastante, não é? Como eles se chamam? A criança citou o nome de todos.

Durante esse diálogo a criança mostrou-se bem descontraída, sorridente, respondendo objetivamente a todas as perguntas que lhe foram feitas.

A finalidade desta conversa, por parte do adulto, foi deixar a criança à vontade, dando tempo para que ela se adaptasse ao meio e fosse diminuída a possivel tensão emocional.

A criança reclamou estar sentido fome e foi-lhe explicado que tão logo terminasse o exame ela poderia tomar sua alimentação normalmente.

No início do exame, quando o médico estava com a sonda na mão, W. olhou para mim. Notei no seu olhar uma expressão de insegurança e um pedido de ajuda. Eu me encontrava um pouco afastada dele. Imediatamente aproximei-me, segurei sua mãozinha, passei a outra mão sobre a sua cabeça e lhe perguntei: 
A - Você está com medo de passar a sonda?

C - Estou!

Expliquei-lhe que iriam passar uma pomada (Xylocaina) no seu nariz (narina) para diminuir a dor e para que a sonda passasse com mais facilidade. Pedi-lhe lambém para que fizesse movimento de deglutição, para facilitar a introdução da sonda.

A - Está bem assim, W.?

C - Está! (Confirmando com movimento da cabeça.)

Permaneci sempre ao seu lado.

D - W., agora vamos passar a sondinha, mas, antes, a tia (funcionária) vai passar uma pomadinha no seu nariz! Qual o "buraquinho" que está melhor para respirar?

C - E este aqui tio! (Apontando a narina direita.) Início da introdução da sonda:

D - W. respire fundo e devagar. W. chorou um pouco e disse: "Tio, está doendo"!

Juntamente com o médico, eu lhe fui explicando como deveria fazer para ajudar na introdução da sonda. W. debateu-se, colocou as mãos no rosto e não foi possível introduzir a sonda pela narina. A médico decidiu resolver a situação de maneira diferente e disse à criança:

D - W., pode deitar-se, mas fique de lado.

Iniciou-se a passagem da sonda pela boca. W. não mais chorou, não se debateu e teve participação ativa na introdução da sonda.

O médico fez a fixação da sonda com esparadrapo e ordenou:

$\mathrm{D}$ - W., pode ditar-se, mas fique de lado.

Comentei:

A - Viu, como foi fácil passar a sonda W.? Você foi bonzinho e ajudou bastante. Doeu para passar a sonda pela boca?

W. fez sinal que não com o dedo indicador.

Durante a aspiração do suco gástrico com a seringa, W. ficou observando, e em dado momento perguntou:

C - Tio, vai demorar muito para tirar a sonda?

D - Vai demorar um pouco sim, uma hora, mas vai ser bom para você porque, fazendo direitinho esse exame, não vai precisar fazer outro novamente; não é melhor assim?

W. respondeu afirmativamente com a cabeça. 
C - Tia, estou com fome!

A - Agora você não pode comer, depois que terminar o exame pode, "Tá"? Dá para aguentar?

C - Está bom, tia!

Continuei sempre ao seu lado, limpando, com gaze, a saliva que escorria da sua boca. Às vezes $W$. pegava na minha mão e olhava para mim. Em dado momento W. perguntou:

C - Tia, ainda vai demorar?

A - Agora vai bem rápido, falta pouco.

O médico confirmou e disse que estava gostando muito de seu comportamento.

W. estava bastante tranquilo e sem queixas. an:

Ao terminar o exame o médico disse:

D - Vamos tirar a sonda W.?

Imediatamente W. sentou-se e, após ser retirado o esparadrapo que fixava a sonda, W. retirou sozinho a sonda, sem nenhuma dificuldade e com muita calma.

Notei com W. saiu da sala de exame animado e sem nenhum ressentimento, apenas referindo estar com fome. Foi-lhe dada a a oportunidade de falar sobre o exame e ele informou não ter sentido dor e que gostou de passar a sonda pela boca mais do que pelo nariz. Não fez nenhum outro comentário. Retroonu à clínica tranquilo, apenas manifestando fome:

C - Tia, agora eu posso comer?

A - Pode! E depois que você tomar café vou dar a você e às outras criano que prometi ontem. Você se lembra do que é?

C - Lembro! É bolo! (Respondeu olhando e sorrindo para mim). Depois comentou:

C - Tia, no almoço vou comer arroz?

A -- Sim! (Expliquei-lhe que a dieta líquida que ele recebeu por dias foi só para que pudesse fazer o exame, mas agora voltaria à sua dieta anterior).

A - Você quer passar a sonda no boneco?

C - Agora não, amanhã eu passo! (Como querendo dizer não quero me lembrar de nada agora).

A - Então eu vou deixar o boneco com você, está bem?

C - Sim! (Apanhou o boneco e levou-o para a enfermaria, guardando-o em seu criado-mudo).

No dia seguinte, quando $W$. fez a dramatização da experiência no boneco, não demonstrou tensão emocional decorrente da situação vivida no dia anterior. 
Diante do comportametno de W. acredito que os objetivos propostos para assistir a esta criança submetida a uma experiência desagradável foram alcançados.

A criança demonstrou estar confiante, pois sabia o que ia acontecer; teve participação ativa durante a experiência; e não demonstrou tensão emocional decorrente da situação vivida.

\section{Experiência $n .^{\circ} 2$}

Nome: M. D. S. Idade: 4 anos. Sexo: masculino. Procedência: Pernambuco.

M. é uma criança pouco sociável em relação às outras crianças; apesar de fazer-lhes companhia, procura não se envolver com qualquer delas; com as pessoas adultas M. é afável e comunicativo.

Possui vocabulário extenso, rico em pronomes, verbos, mas, apresenta articulação infantil; conserva a entonação peculiar de sua terra natal. Gosta de tomar decisões e usa a negação, com freqüência, ao ser solicitado por outras pessoas. Apresenta boa coordenação motora fina e comportamento adaptativo próprio da idade. Não tem capacidade de compreender a gravidade de seu estado.

M. parece adaptado ao meio ambiente, sendo comunicativo com o pessoal de saúde. Costuma cooperar no seu tratamento e nos cuidados que lhe são prestados, principalmente quando é informado sobre o que vai ser feito. Gosta de ser examinado pelo seu médico, com exceção da palpação abdominal, devido à dor. Apresenta reação de pânico diante da situação do curativo da incisão cirúrgica. Deprime-se facilmente e torna-se irritado devido às modificações de seu estado geral.

M. é portador de neoblastoma do fígado. Já foi operado e está no pós-operatório mediata, apresentando sinais de complicações: náuseas e vômitos. Está desidratado e bastante debilitado.

Considerações sobre a experiência desagradável.

A experiência que M. vai viver é a passagem de sonda naso-gástrica.

As fontes de desconforto identificadas para esta situação são as seguintes:

— incômodo, causado pela introdução da sonda;

- produção de reflexos, causando náuseas, vômitos e tosse;

- ardor na garganta devido a permanência da sonda.

Assistência de enfermagem à criança na situação desagradável.

O ideal para a assistência de enfermagem, nesta situação, seria ter havido tempo para prepará-la com antecedência, através da dramatização no boneco, onde ela poderia manusear o material e receber as informações pertinentes à experiência a ser vivida. Isto não foi possível, pois a decisão de passar a sonda não havia sido 
planejada com antecedência; foi decorrente das condições em que se encontrava, com a apresentação de vômitos. A assistência foi ocasional e, no diálogo abaixo, com a aluna (A) e o médico (D), está demonstrado como ocorreu e qual foi o comportamento da criança $(\mathrm{C})$.

M. estava sentado na cadeira de rodas e recebia "soro de expansão". Ao ouvir a conversa de dois médicos que estavam a sua frente, começou a chorar desesperadamente. Aproximei-me e perguntei-lhe:

A - Porque está chorando, M.?

C - Eu não quero sonda!

A - Mas quem falou que vai colocar sonda?

C - Foi aquele tio, (e apontou para um dos médicos presente). Dirigi-me ao médico, que confirmou a passagem da sonda.

A - E verdade M., aquele tio disse que precisa passa uma sondinha aqui pelo nariz.

C - Eu não quero! Eu tenho medo! (gritou, chorando).

A - Sabe ,M., aqui dentro da barriguinha (colocando a mão sobre o seu estômago) está cheio de líquido que incomoda e faz você vomitar, umas tantas vezes.

C - Eu não que "botá" a sonda, tia!

A - Mas, para tirar este líquido dai de dentro e para você não vomitar mais, é preciso. Isto vai ajudar você a sentir-se melhor e poder tirar este "soro".

Continuou chorando, mas sem a expressão de desespero inicial. Foi repetido que iriam passar a sonda só para ajudá-lo a melhorar.

Preparei o material e aproximei-me novamente de M. informando-o:

A - Vou passar esta pomadinha na sonda que é para entrar mais fácil.

C - Mas, doi, tia!

A - Pode doer um pouco a garganta, mas, se você ajudar a tia, vai ser mais fácil, "tá"?

$\mathrm{C}$ - Eu tenho medo !

A - Então segure bem firme a mão desta tia (enfermeira que estava a meu lado orientando-me) e pode chorar se doer, mas não mexa a cabeça que eu passo a sondinha bem ligeiro e não machuco o seu nariz "tá" certo?

M. concordou, fazendo um gesto com a cabeça.

A enfermeira auxiliou-o a manter os braços e a cabeça numa posição que facilitasse o procedimento da pasagem da sonda e mantivesse o "soro" correndo.

A - Agora eu vou colocar a sonda, não mexa a cabeça e vá engolindo. (Introduzi a sonda sem dificuldades.) 
M. chorou, apresentou náuseas e tosse, mas não mexeu a cabeça nem os braços, ficou segurando fortemente a mão da enfermeira o tempo todo. Parou de chorar logo que terminei de introduzir a sonda.

Abri a sonda e coloquei a extremidade no saquinho coletor. Mostrei-lhe o liquido que saía e expliquei-lhe:

A - Agora o líquido vai para o saquinho e você não vomita. Concordou e mostrou-se tranqüilo.

A - Doeu, M.?

C - Não! Eu quero passear!

A - Então vamos passear um pouquinho!

$\mathrm{C}$ - Eu quero passear agora, tia!

Ele merecia uma compensação! Levei-o para passear pelo corredor.

Algum tempo depois $M$. começou a vomitar novamente e chorava quando se ia aspirar a sonda, pois esta se havia desprendido. $O$ médico aproximou-se para arrumar a sonda e disse-lhe:

D - Fique quieto que eu vou arrumar esta sonda! (Falou em tom alto.)

O menino assustou-se, movimentou a cabeça bruscamente e a sonda saiu.

D - Viu M. agora eu vou ter que passar a sonda novamente (o tom de voz do médico era ameaçador).

C - Não quero ,eu não vomito mais! (M. chorou: estava assustado com a atitude do médico).

D - Deita aqui na cama e nós vamos passar outra sonda!

C - Quero ficar aqui na cadeira sentado!

Resolvi intervir:

A - M., fique sentadinho na cama enquanto eu vou buscar outra sonda. (Coloquei-o sentado na cama de maneira delicada.)

C - "Tá" bom, tia!

Tentei acalmá-lo um pouco, mas o médico não me deu oportunidade.

Providenciei o material e tentei ajudar a criança, mas, o médico estava decidido a deitá-lo à força e passar a sonda logo, para não perder tempo. o medo.

M., começou a gritar e na sua fisionomia mais uma vez se via o desespero e

Houve necessidade de três pessoas para segurá-lo, porque ficou muito agitado, batendo os braços e pernas, querendo impedir a passagem da sonda. 
O médico colocou Xylocaina diretamente numa de suas narinas e, comprimindo a outra, disse em tom alto:

D - "Respire" M., chupe o ar assim (e demonstrou).

C - M. não queria, mas, acabou inspirando um pouco de Xylocaina, chorando muito.

O médico introduziu a sonda rapidamente e fixou-a bem com o esparadrapo. A criança parou de chorar e continuou olhando assustada para o médico que ainda dizia:

D - Viu só? Precisava chorar deste jeito?

A criança olhou para mim e disse:

C - Tia, eu quero ficar na cadeira!

A - Está bem, eu o coloco na cadeira! Agora escute, a tia ajudou a segurar com força o seu braço, porque, senão, o "sorinho" ia sair do braço e eu quero que você fique bom logo.

M. concordou.

Coloquei-o na cadeira de rodas e levei-o para junto das outras crianças.

$\mathrm{C}$ - Eu quero passear no corredor!

A - Agora eu não posso passear com você porque está na hora de ir embora, preciso almoçar e ir para a aula. Eu volto amanhã.

C - Então eu quero ficar na cama!

Levei-o para a cama e ele ficou quieto olhando-me. Despedi-me e ele sorriu dando "tchau".

Pelas reações de M. pude notar ter ele aceito melhor a experiência, na primeira vez, quando lhe foi dado uma explicação do que iria acontecer, mesmo que esta não tenha sido com tempo suficiente para prepará-lo melhor.

Na primeira vez ele reagiu de maneira natural e na segunda experiência suas reações foram violentas, em resposta à maneira como estava sendo tratado.

Dadas as condições em que ele se apresentava, deduzi que estas duas experiências de passar sonda naso-gástrica não seriam as únicas e resolvi prepará-lo melhor. No dia seguinte levei um boneco para demonstrar a passagem de sonda, isto é, fazer a dramatização da situação.

Quando achei oportuno, levei-o para sua cama e disse-lhe que iriamos brincar de passar sonda no boneco, o que ele achou interessante, assim como todas as outras crianças.

Levei todo o material, sonda, tubo de Xylocaina e esparadrapo para perto da cama. Cortei tiras de esparadrapo e coloquei Xylocaina na sonda. Reforcei as explicações a respeito de "porque" passar a sonda e pedi a colaboração de M. a 
cada passo da dramatização. Em seguida, ele quis passar a sonda sozinho. Queria introduzir toda a sonda, dizendo que o médico fazia assim e colocou esparadrapo na testa do boneco como fez o médico com ele. A dramatização serviu então para a criança demonstrar como havia percebido a experiência vivida com o médico.

Naquela mesma tarde, houve necessidade de passar a sonda novamente em M., porque estava apresentando nova crise de vômitos. Uma colega teve oportunidade de presenciar e constatar o resultado do preparo no comportamento da criança. $\mathrm{O}$ menino comportou-se de maneira diferente durante a experiência. Ele pediu para que não segurasse a sua cabeça. Inspirou espontaneamente um pouco de Xylocaina e pediu para segurar a mão do médico que iria passar a sonda, participando da mesma. Resmungou um pouco, como é natural. Afinal é incômodo sentir a sonda no nariz e na garganta, mas não movimentou a cabeça e cooperava quando lhe pediam para ajudar, engolindo a sonda.

\section{Avaliação da assistência.}

Diante das reações da criança, posso concluir que a comunicação foi significativa porque houve mudança no seu comportamento, passando a cooperar numa situação difícil e tão desagradável para ele.

\section{COMENTÁRIO FINAL}

Em ambas as experiências parece ter ficado evidente a influência da assistência prestada às duas crianças que enfrentavam a passagem de sonda naso-gástrica.

A assistência de enfermagem prestada pelas alunas às duas crianças que viveram esta situação consistiu principalmente em:

- dar informações do que iria acontecer; qual a finalidade da experiência; o que elas iriam sentir e o que deveriam fazer para cooperar e facilitar o andamento da experiência;

- mostrar o material a ser utilizado durante a experiência, deixando a criança manuseá-lo e usá-lo no boneco, prévia e/ou posteriormente à situação;

- dar apoio à criança durante a situação, permanecendo ao seu lado e oferecendo-lhe oportunidade para expressar o desconforto causado pela introdução da sonda; dar informações sobre o andamento da experiência; elogiar a atitude de cooperação;

- dar oportunidade para demonstrar os sentimentos despertados pela situação vivida, através do diálogo e da tramatização no boneco.

A participação ativa das duas crianças na experiência, durante a assistência prestada pelas alunas, e a ausência de sinais de tensão e ressentimento em ambas vieram confirmar o que BELLACK ${ }^{2}$ afirmou: "quando é dada à criança um encorajamento, preparo e atendimento das suas necessidades, antes, durante e após o tratamento, a maioria das crianças fica mais bem equipada para enfrentar a situação estressante". O contrário também parece ter ficado demonstrado: quando a situação é imposta à criança, sem consideração por sua capacidade de cooperar, 
suas reações são evidentemente diferentes. Isto foi constatado no relato número 2 , quando o médico impediu a aluna de dar a devida atenção à criança, impôs condições para a recolocação da sonda e falou com ela em tom áspero; a criança não cooperou, reagiu mal e precisou ser restringida por três pessoas. Ficou evidente também, neste relato número 2, o que ERICKSON"3 afirmou: "quando é dada à criança oportunidade de brincar com instrumentos clínicos ela demonstra seus sentimentos a respeito de experiências no hospital".

Para as alunas a experiência parece ter sido muito significativa, pois perceberam o resultado de sua atuação junto à criança. Não só elas próprias constataram o benefício da assistência prestada; o médico da criança do relato número um constatou o mesmo, procurando, posteriormente, a docente responsável pela aluna que havia assistido à criança, e solicitou-lhe a presença da mesma junto ao W. em novo exame, comentando: "aquela sua aluna conseguiu que $W$. cooperasse de maneira fabulosa na vez anterior; seria muito bom que ela pudesse ajudar de novo".

MARTINS, D. M. R.; OHKI, A. E.; FELLI, V. E. A. Nursing assistance to hospitalized children instraightened circunstances. Rev. Esc. Enf. USP, São Paulo, 13(2): 157-169, 1979.

In this article, the first of a series, there were related two experiences of nursing students in pediatrics, helping the hospitalized children to cope with difficult circunstances, as to say, the inserting of a naso-gastric tube.

\section{REFERENCIAS BIBLIOGRAFICAS}

1. BARTON, P. H. - Play as a tool of nursing. Nurs. Outlook, New York, 10: 162-4, 1962.

2. BELLACK, J. P. - Helping a child cope with the stress injury. Amer. J. Nurs., New York, 74(8): $1491-4,1974$

3. ERICKSON, F. - Reactions of children to hospital experiences. Nurs. Outlook, New York, 6(9): $501.4,1958$.

4. ERIKSON, E. H. - Infância e sociedade. Rio de Janeiro, Zahar, 1971, p. 204.

5. MORAES, E. - Guias de estudo de enfermagem pediátrica. Rev. Esc. Enf. USP, São Paulo, 6(1 e 2): 83-9 e 118-23, 1972.

6. PIAGET, J. - PTay, dreams and imitation in childhood. Translated by $C$. Gattegno and $F$. M. Hodgson, New York, W. W. Norton, 1952. p. 148-9.

7. SMITH, M. - Ego support for the child patient. Amer. J. Nurs., New York, 63(10): 90-5, 1963.

8. WU, R. - Expling treatments to young children. Amer. J. Nurs., New York, 65(7): 71-3, 1965. 